\title{
Organic consumers' profile beyond the mean
}

\author{
Marilena Furno $\mathbb{D}$ - Teresa Del Giudice • Gianni Cicia
}

Received: 24 January 2019 / Accepted: 13 November 2020 / Published online: 13 January 2021

(C) The Author(s) 2021

\begin{abstract}
The European organic food market is characterized by very different consumer segments. There are significant differences concerning motivations for organic food consumption, preferences for various attributes, and frequency of purchase among consumers. Although the organic food sector has been studied for about 20 years, little is known about consumer behavior at different levels of consumption. The aim of this study was to investigate the determinants of organic food consumption in various market segments characterized by different purchasing frequencies. The determinants of purchase frequency in Italy and Germany are analyzed not only at the mean regression, by OLS, but also at the median and at the mode. Differing estimates at these measures of central tendency generally occur with asymmetric distributions, and this occurs in the following analysis as well. Moreover, since in Germany the dependent variable presents more than one peak/mode, interpretation of the mode regression becomes problematic and a different tool is implemented, namely the finite mixture model. The latter clusters the observations in homogeneous groups while computing the regression
\end{abstract}

\footnotetext{
M. Furno $(\bowtie) \cdot$ T. Del Giudice $\cdot$ G. Cicia

Department of Agricultural Sciences, Università degli Studi di Napoli "Federico II", Naples, Italy

e-mail: marfurno@unina.it
}

T. Del Giudice

e-mail: agriqual@unina.it

G. Cicia

e-mail: cicia@unina.it coefficients within each group. Buyers are split into two groups, frequent and rare consumers of organic food, and two different sets of estimated coefficients explain frequency of purchases within each group.

Keywords Organic food - Quantile regression · Mode regression · Finite mixture model

\section{Introduction}

Consumer demand for organic products is growing worldwide (Du et al. 2017), and the search for the factors driving organic consumption is assuming increasing importance. Twenty years ago, consumers chose organic products mainly for reasons of food safety and eco-friendliness (Zanoli and Naspetti 2002; de Magistris and Gracia 2008; Cicia et al. 2009). More recently, a growing number of authors have underlined the role of attribute perception in the motivation for organic purchases (Yiridoe et al. 2005; Krystallis et al. 2006; Zander and Hamm 2010; Lee and Yun 2015). Both general and commodity-specific attributes affect consumers' choices of organic food (Hansen and Andersen 2013). General attributes are related to various issues such as food safety, human health, environmental impact, fair wages, and farm animal welfare (Hughner et al. 2007; Naspetti and Zanoli 2009; Wee et al. 2014; Gerini et al. 2016; Di Fonzo and Liberati 2020). Commodity-specific attributes include visual appeal, nutritional value, taste, and freshness (Cicia et al. 2002; Bi et al. 2015; Hempel and Hamm 2016). Of the 
latter attributes, perception of nutritional content, ecological welfare, price, freshness, and sensory characteristics have a strong effect on determining behavioral intentions to purchase organic food (Cicia et al. 2002; Wee et al. 2014). Several attributes are also related to consumers' expression of their identities and life values (Krystallis et al. 2012; Hwang et al. 2015).

Given the new dimensions of consumer quality perception, a modern analysis of consumer preferences for food, especially organic food, has to consider extrinsic attributes as important elements to determine quality before purchase (Grunert 1996). The most commonly studied extrinsic attribute is product origin. Numerous studies (Scarpa and Del Giudice 2004; Dekhili et al. 2011; Panico et al. 2011; Cicia et al. 2013; Profeta et al. 2012; Klockner et al. 2013) show that information on product origin positively influences consumer preferences. Some authors (Denver and Jensen 2014) show two separate dimensions for perceptions of organically and locally grown products. A positive perception of product origin has been shown to influence the preference for organic certification.

Recent analyses show that most consumers of organic food are concerned about additional ethical attributes (Zander and Hamm 2012). It has been shown (Arnot et al. 2006; Schleenbecker and Hamm 2013) that consumers are particularly interested in good conditions for workers, fair prices for farmers, and animal welfare. With respect to sustainability, increasing attention has been given to the reduced use of pesticides, low environmental impact of the production process, low carbon footprint, and compostable/recyclable packaging (Annunziata and Vecchio 2016; Verain et al. 2016; de Magistris and Gracia 2016). According to some authors (Hall et al. 2010; Koutsimanis et al. 2012), packaging material is perceived as a new aspect that influences fresh food quality and, if natural and biodegradable, it is preferred to other less sustainable solutions.

Despite the above changes in consumer demand, the organic food market is still relatively small compared to the whole food sector. Regular and occasional buyers both characterize the organic market (Jensen et al. 2011). A small market share and consumer segments with different levels of demand make it difficult to ascertain the preferences, quality perception, and organic purchasing motives for both regular and occasional consumers.

Most of the research on purchases and consumption of organic food do not differentiate the various levels of organic demand. In general, low consumption and high consumption segments are analyzed separately (Baudry et al. 2017; Buder et al. 2014). Few studies explore purchasing frequency to explain consumer behavior (Pearson et al. 2013).

This study focuses on the determinants of organic food purchases among buyers with different purchasing frequencies. This allows us to address the relevance of the perception of various food attributes across consumers with differing socioeconomic patterns.

The analysis of food choice determinants within consumer segments is implemented on a national level. Our aim was to estimate the effect of food attributes on consumers with different organic food purchasing frequencies for two representative national consumer samples. The determinants of organic food purchasing frequency are analyzed not only at the mean regression, by OLS, but also at the median and at the mode. Differing estimates at the various measures of central tendency generally occur with asymmetric distributions, as is the case in our study. Due to skewness, the estimates for the average frequency of purchases differ from those describing the behavior of half-sample, the median, which in turn differ from the estimates describing the most recurring purchase frequency, the mode. While we find great homogeneity in the determinants of the demand for organic food across estimators, the estimated coefficients differ according to the estimator implemented. In other words, the OLS regression provides a poor interpretation of the variable under study, and the impact of the determinants of consumer demand changes along the distribution, whether the focus is on average, on half-sample, or on the highest frequency of purchases.

For the mode regression, a caveat is in order. If the distribution of the dependent variable presents more than one peak, interpretation of the results of the mode regression becomes problematic. An example is provided by the distribution of organic food in the German data. In this dataset, frequent buyers are the modal group, but people buying once a month are almost as numerous, and interpretation of the mode regression results becomes blurred. Therefore, a different approach is considered, modeling frequency of purchases as a mix of two distinct distributions, one for rare buyers and one for frequent buyers. The finite mixture model allows observations to be split into homogeneous groups while computing the regression coefficients within each group. Explicit modeling of two distinct groups of consumers shows a wide difference in the determinants of 
purchasing frequency in Germany. The two groups clearly differ in the determinants of purchases: most explanatory variables are irrelevant in the rare buyers' subset, while for the weekly buyers, almost all the selected variables contribute to determine their frequency of purchases.

Finally, the determinants of organic food purchases are estimated in the tails, away from the central measures of location. These results confirm that the coefficients do change according to the selected frequency of purchases. Considering their absolute value, the estimated coefficients show an increasing pattern in going from the left to the right tail of the dependent variable, from low to high purchase frequency. Once again, this signals the importance of defining the appropriate target of the study and shows the potentially misleading role of the average/OLS model.

"Questionnaire and data" describes the data collection methodology; "Methods and models" defines the model and the various estimators implemented; "Estimation results" presents the results of our analysis. "Discussion" is dedicated to the discussion, and the last section draws conclusions.

\section{Questionnaire and data}

The data were collected through a questionnaire distributed by a professional marketing company. The interviewees were those responsible for major household food purchasing decisions. To obtain a representative sample, consumer stratification was based on geographical area and demographic size of municipalities of residence as reported by the Italian National Institute of Statistics and the Federal Statistical Office of Germany. Within each territorial unit, interviews were conducted to meet quota targets for gender and age group. The two organic product markets are very different. Germany shows a higher per capita consumption and a more mature organic sector compared to its Italian counterpart, where the organic market is still at an initial stage. The sample was of size $n_{\mathrm{G}}=1009$ in Germany and $n_{\mathrm{I}}=1004$ in Italy.

Table 1 shows a fairly balanced sample with respect to gender in Germany and the preponderance of women in Italian food shopping. Income distribution shows a preponderance of moderate incomes with quite a large percentage of non-responses in Germany. In terms of education, the largest percentage in Germany is represented by graduates, while high school is the Italian mode.

The first part of the questionnaire dealt with consumer food purchasing behaviors. This section asked questions concerning the consumer's frequency of buying organic food and their level of knowledge about organic certification. After a brief introduction the following critical question was posed: "When you buy food how often do you buy organic certified food?'. Six alternatives were given: (1) never; (2) seldom; (3) once a month; (4) two or three times a month; (5) once a week; (6) more than once a week.

Figure 1 shows the pattern of organic food purchases in Italy and in Germany. The Italian distribution is positively skewed while in Germany the distribution is bimodal. In Germany, the mean, marked by an $\mathrm{x}$ in the pictures, is smaller than the median, marked by an 0 , which is smaller than the upper quartile, marked by an asterisk. The plus mark signals the position of the lower quartile. The bimodal aspect of organic food in Germany yields a small negative skewness of -0.09 . The first peak occurs at rare purchases and has a frequency of 243 while the second peak occurs at weekly purchases and has a frequency of 246. The two values are very close to one another, with a slight dominance of the weekly buyers' frequency. In Italy, the mode is smaller than the median, which in turn is smaller than the mean, thus yielding a positive skewness of 0.95 .

The second part of the questionnaire was devoted to collecting information about the importance attached by consumers to various characteristics of a (generic) food product. Seven attributes related to new dimensions of quality perception are selected. As described in the previous section, this analysis focuses on extrinsic food characteristics.

The key question is "The following are some characteristics that define the quality of food products. Please indicate how important each of them is for you to define food quality, using a score from 1 to 7 , in which ' 1 ' means that for you it is 'completely unimportant,' while ' 7 ' means that it is 'extremely important."' The seven attributes listed to rate are (1) price [PRICE]; (2) product origin certified by European labels, namely Protected Designation of Origin (PDO) and Protected Geographical Indication (PGI) [CERTIFIED]; (3) biodegradable packaging (ECOPACK); and (4) lack of pesticides - also known as agricultural chemicals used to protect plants against pests. They include herbicides and insecticides [NO CHEMICALS]; (5) low 
environmental impact of the production process [LOW IMPACT]; (6) low $\mathrm{CO}_{2}$ in transportation [ECO TRANSPORT]; and (7) fairly paid work [FAIR WAGE]. Italy shows higher sample means and smaller standard deviations for this set of variables.

The third part of the questionnaire comprises questions relating to the consumer's sociodemographic profile like age [AGE] in the range 18-79 in Germany and from 19 to 86 in Italy; education [EDUCATION] increasing from 1 to 8 with a university degree; presence of children under 10 years old [CHILDREN], a dummy variable; household income [INCOME] ranging from 1 to 3 as income increases from low to high; occupation ranging from unemployed to entrepreneur and split into two dummies [SELF-EMPLOYED] and [EMPLOYEES] ${ }^{1}$; gender [GENDER] a dummy variable for women, regional differences. This variable is a dummy [NORTH] assuming a unit value for the northern regions. It has been tested but resulted not statistically significant. Tables 1 and 2 report the summary statistics, means, and standard deviations of the model variables.

\section{Methods and models}

The model is first estimated by OLS, which measures the average impact of the explanatory variables on the frequency of purchases, i.e., the conditional mean. It is then computed at the median and at the mode, thus showing respectively the impact of the covariates for half of the sample and at the peak of purchasing frequency. Mean, median, and mode are relevant characteristics of a distribution, particularly in the case of skewness, when such measures of central tendency diverge. While OLS is affected by the presence of anomalous values, the other two estimators are robust to outliers. They are implemented as weighted least squares, each having a different definition of the weighting system.

\footnotetext{
${ }^{1}$ Household income considers household resources, while profession refers to an individual. By splitting the latter into self-employed and employees, this variable looks at the variability in individual resources, volatile for the self-employed and more stable for employees. In Table 1, employment is grouped into self-employed, employees, unemployed, and pensioners/housewife/students. The last two categories, those officially unemployed and pensioners/housewife/students, are excluded from our model.
}

Table 1 Sociodemographic characteristics of the sample

\begin{tabular}{|c|c|c|}
\hline & Germany & Italy \\
\hline \multicolumn{3}{|l|}{ Gender $(\%)$} \\
\hline Male & 45.49 & 13.25 \\
\hline Female & 54.51 & 86.75 \\
\hline Age (years): & $\begin{array}{c}\text { Mean }=42.4(\text { st. } \\
\text { dev. }=13.14)\end{array}$ & $\begin{array}{c}\text { Mean }=52.5 \text { (st. } \\
\text { dev. }=14.37)\end{array}$ \\
\hline \multicolumn{3}{|l|}{ Children $<10$ years old $(\%)$} \\
\hline Yes & 20.6 & 18.3 \\
\hline No & 79.4 & 81.7 \\
\hline \multicolumn{3}{|l|}{ Income } \\
\hline$<1500$ Euro/month & 22.8 & 25.2 \\
\hline 1500-3050 Euro/month & 39.3 & 36.9 \\
\hline > 3050 Euro/month & 23.3 & 36.6 \\
\hline No answer & 14.6 & 1.2 \\
\hline \multicolumn{3}{|c|}{ Highest qualification completed } \\
\hline$<$ High school & 11.8 & 31.3 \\
\hline High school & 22.5 & 40.4 \\
\hline University degree & 28.9 & 15 \\
\hline \multicolumn{3}{|l|}{ Employment } \\
\hline Self-employed & 11.1 & 15.2 \\
\hline Employed & 60.36 & 35.2 \\
\hline Unemployed & 4.95 & 3.18 \\
\hline $\begin{array}{l}\text { Housewife, students, } \\
\text { pensioners }\end{array}$ & 23.58 & 46.31 \\
\hline Sample size & 1009 & 1004 \\
\hline
\end{tabular}

The table reports the sample means/proportions and, when appropriate, the standard deviations of the variables within each country

\section{Quantile regression}

Consider the simple linear regression model $y_{\mathrm{i}}=\alpha+\beta x_{\mathrm{i}}$ $+e_{\mathrm{i}}$, with $y_{\mathrm{i}}$ being the frequency of purchases and $x_{\mathrm{i}}$ the explanatory variable. The median regression (Koenker 2005) computes the regression passing through the median of the conditional distribution of the dependent variable, just as OLS goes through the mean. Compared to OLS, it reduces the relevance of large residuals since it is defined in terms of the absolute value of the errors instead of the squared errors. The median regression, through its weighting system, splits the residuals in exactly two halves, half above and half below the estimated regression line. The quantile regression objective function considers the weighted sum of the absolute value of the errors, $\Sigma_{\mathrm{i}} w_{\mathrm{i}}\left|e_{\mathrm{i}}\right|=\Sigma_{\mathrm{i}} w_{\mathrm{i}}\left|y_{\mathrm{i}}-\alpha-\beta x_{\mathrm{i}}\right|$. At the median, the weights are symmetrical, $w_{\mathrm{i}}=0.5$, and the objective function is $\Sigma_{\mathrm{i}} 0.5\left|y_{\mathrm{i}}-\alpha-\beta x_{\mathrm{i}}\right|$. An asymmetric 


\section{Organic food purchases}
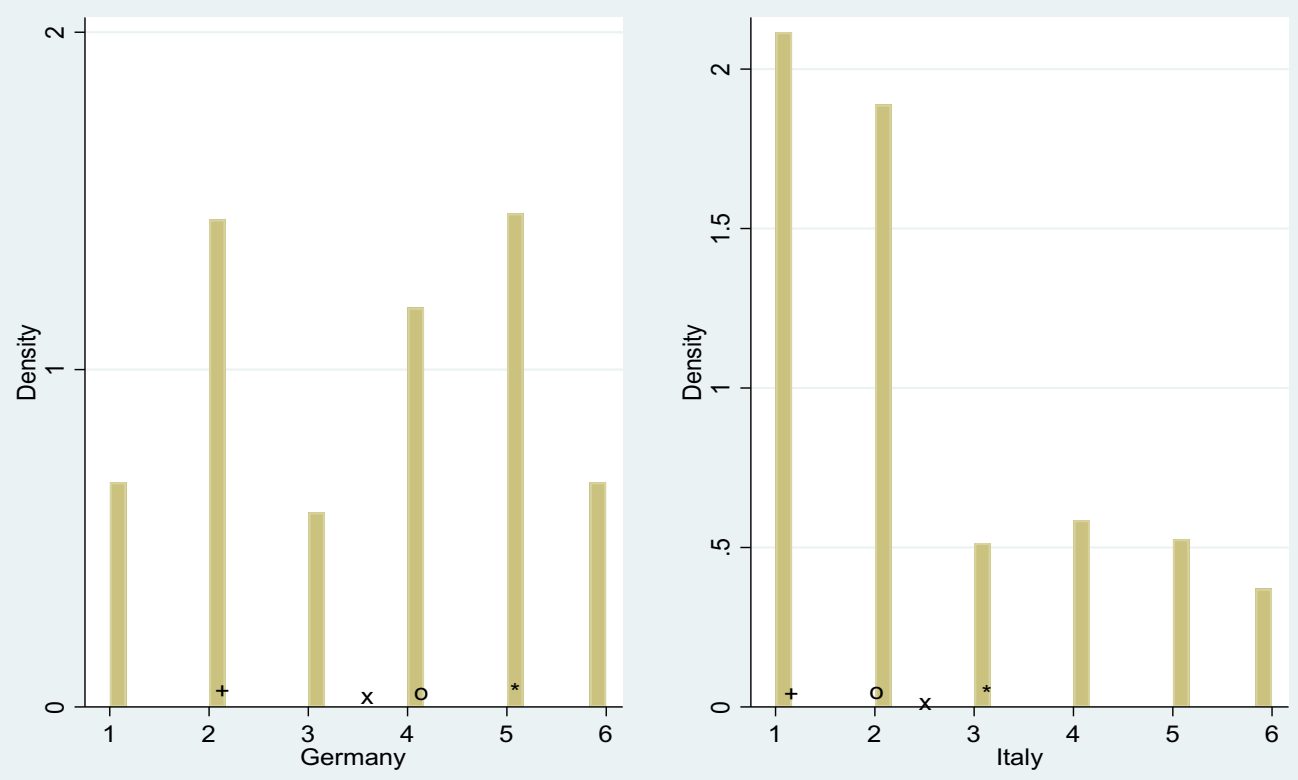

Fig. 1 Histograms of the organic food purchases in Germany and in Italy. In Germany, the mean, marked by " $x$ " in the pictures, is smaller than the median, marked by "o," which is smaller than the upper quartile, marked by an asterisk. The plus mark signals the

position of the lower quartile. The bimodal aspect of organic food in Germany yields a small negative skewness. In Italy, the mode is smaller than the median, which in turn is smaller than the mean. This is due to the positive skewness of the distribution

weighting system moves the estimated regression away from the center. The weights are defined as

$$
\begin{aligned}
& w_{\mathrm{i}}=\theta \text { if } e_{\mathrm{i}}>0 \\
& =1-\theta \text { if } e_{\mathrm{i}}<0
\end{aligned}
$$

For instance, to compute the $\theta=0.25$, which estimates the model when purchases at farmers' markets are rare, $w_{\mathrm{i}}$ assigns weights $w_{\mathrm{i}}=1-\theta=0.75$ to those

Table 2 Product characteristics, values 1 to 7 on a Likert scale

\begin{tabular}{lll}
\hline & $\begin{array}{l}\text { Germany } \\
\text { Mean (st. dev.) }\end{array}$ & $\begin{array}{l}\text { Italy } \\
\text { Mean (st. dev.) }\end{array}$ \\
\hline NO CHEMICAL & $4.89(1.56)$ & $6.38(1.09)$ \\
CERTIFIED & $5.46(1.38)$ & $6.00(1.16)$ \\
PRICE & $4.56(1.61)$ & $5.56(1.49)$ \\
LOW IMPACT & $4.54(1.64)$ & $5.75(1.38)$ \\
FAIR WAGE & $4.46(1.68)$ & $5.47(1.52)$ \\
ECO TRANSPORT & $4.92(1.52)$ & $6.14(1.17)$ \\
ECOPACK & $4.86(1.54)$ & $5.60(1.40)$ \\
Sample size & 1009 & 1004 \\
\hline
\end{tabular}

observations below the regression, thus attracting the estimated line toward the lower tail, while it assigns weights $w_{\mathrm{i}}=\theta=0.25$ to the observations above the line. The larger weight attributed to the lower observations moves the estimated line toward the left tail of the dependent variable, thus modeling rare buyers. The opposite occurs at the 75 th quantile, which computes the impact of the explanatory variables on regular buyers: the weights are switched and $w_{\mathrm{i}}=1-\theta=0.25$ is assigned to the observations below the regression and $w_{\mathrm{i}}=\theta=0.75$ to those observations above it. The purpose of quantile regressions is to ensure against anomalous values, skewness, and kurtosis.

\section{Mode regression}

The mode regression (Lee 1989) computes the line passing through the mode of the error distributions, thus focusing on most of the data. This ensures the great robustness of the mode regression estimator. Furthermore, while other robust estimators lose efficiency in the case of normality, this is not the case for the mode regression. The mode regression can be defined as a 
weighted least squares estimator, $\Sigma_{\mathrm{i}} w_{\mathrm{i}} e_{\mathrm{i}}^{2}$, with weights given by (Kemp and Santos Silva 2012):

$w_{\mathrm{i}}=\exp \left[-e_{\mathrm{i}}^{2} /\left(2 \delta^{2}\right)\right]$

where the bandwidth parameter $\delta$ is a function of the median absolute deviation (MAD):

$$
\begin{aligned}
\delta & =0.5 n^{-1 / 7} \operatorname{MAD}\left(e_{\mathrm{i}}\right) \\
& =0.5 n^{-1 / 7} \operatorname{median}\left|e_{\mathrm{i}}-\operatorname{median}\left(e_{\mathrm{i}}\right)\right| .
\end{aligned}
$$

The bandwidth defines the selected measure of central tendency. A small $\delta$ yields the mode regression while a large $\delta$ computes OLS. The mode regression, that is a robust estimator as well, computes the impact of the explanatory variables exactly at the highest frequency, to explain not the average but the most frequent value of the dependent variable.

Finite mixture

In the German case, the distribution is bimodal, and it may be interesting to explicitly model this characteristic. A mixture of two normal distributions with the same variance but with different means yields a bimodal distribution and is suitable for modeling the characteristics of the German distribution of organic food demand. The presence of an unobservable latent variable $z_{\mathrm{i}}$ assigns the observation to one of the two normal distributions. The maximum likelihood objective function is $\sum \pi_{\mathrm{i}} f\left(y_{\mathrm{i}} \mid x_{\mathrm{i}}, z_{\mathrm{i}}=1\right)$, where $\pi_{\mathrm{i}}$ is the probability of an observation belonging to a group and is a function of the non-observable variable $z_{\mathrm{i}}$,

$\pi_{\mathrm{i}}=\pi\left(z_{\mathrm{i}}=1\right)=\exp \left(z_{\mathrm{i}}\right) / \Sigma_{j=1, \mathrm{k}} \exp \left(z_{\mathrm{i}}\right)$

where $k$ is the number of groups in the model, in this case $k=2$, and $z_{\mathrm{j}}$ is approximated by additional explanatory variables which in this model are the socioeconomic variables. The estimates are computed iterating between the estimated expected probability of belonging to a specific group as estimated by the logit model $\pi_{\mathrm{i}}=\exp .\left(z_{\mathrm{i}}\right) / \Sigma_{\mathrm{j}=1, k} \exp \left(z_{\mathrm{j}}\right)$, and the estimates of the regression coefficients for that group, $\sum \pi_{\mathrm{i}} f\left(y_{\mathrm{i}} \mid x_{\mathrm{i}}, z_{\mathrm{i}}=\right.$ $1)$. This approach allows us to model bimodal distributions and more generally finite mixtures of distributions.

\section{Estimation results}

The market for organic products differs markedly in the two countries. Germany shows a per capita consumption of organic products that is almost three times greater, in value, than that of Italy: 93.60 Euro per year in Germany versus 33.00 Euro per year in Italy (Italian Trade Agency 2018). This is reflected in purchasing frequencies, as can be seen in Table 3 . In terms of shares of organic food sales, in Italy, the organic market is still in its infancy, while in Germany, it seems more mature (von Meyer-Höfer et al. 2015).

Figure 1 reports the histograms of organic food purchases in Germany and in Italy. Their unconditional distributions are both skewed: the former is bimodal and the other is asymmetric to the right.

The discrepancy across countries is also reflected in a differing set of determinants of organic food purchases in each country, and in a differing pattern of results across estimators. The same set of variables was considered in both countries.

The Italian case

In Italy, the estimated coefficients reduce their impact on the dependent variable when moving from the OLS/

Table 3 Purchase frequency percentages

\begin{tabular}{cllllll}
\hline Germany & Never $=1$ & Seldom $=2$ & Once a month $=3$ & $2 / 3$ times a month $=4$ & Once a week $=5$ & $>$ once a week $=6$ \\
Organic food & 11.1 & 24.1 & 9.6 & 19.7 & 24.4 & 11.1 \\
Organic food & & Mean $=3.55$ & Median $=4$ & Mode $=$ & 0.25 & Skewness $=-0.09$ \\
& & & & 0.75 quartile $=5$ & quartile $=2$ & \\
Italy & Never $=1$ & Seldom $=2$ & Once a month $=3$ & $2 / 3$ times a month $=4$ & Once a week $=5$ & $>$ once a week $=6$ \\
Organic food & 35.3 & 31.5 & 8.6 & 9.7 & 8.7 & 6.1 \\
Organic food & & Mean $=2.44$ & Median $=2$ & Mode $=$ & 0.75 & Skewness $=0.95$ \\
& & & 0.25 quartile $=1$ & quartile $=3$ & \\
\hline
\end{tabular}


conditional mean to the conditional median and mode. This means that the impact of the coefficients is reduced in moving from occasional buyers to non-buyers of organic products. Education, certified label, and ecological transportation have a positive impact on organic food purchase frequency which is greater on average, somewhat smaller at the median and even smaller at the mode (Table 4). Less frequent buyers and non-buyers are less well-educated and have less interest in certified food and in sustainable food transportation. Therefore, the average impact on the dependent variable is sizably overestimated compared with the results at the median and more so at the mode, for most buyers. Fair wage is not statistically significant at the mean but is positive and statistically significant at the median and at the mode. Thus, frequent buyers have a higher preference for fair wage. The negative impact of price is less relevant at the median and at the mode, since both results are smaller than the OLS estimates in absolute value. This outcome is useful to learn about pricing strategies for buyers with different purchase frequencies. Although organic products are generally more expensive, less frequent buyers and non-buyers care less about food price. This could mean that they choose not to buy organic for reasons other than price. The differing results across estimators show that the average/OLS estimate provides an incomplete picture of the model. By comparing different measures of location, it becomes clear that the impact of the explanatory variables on organic food changes when looking at the mode or at the median frequency of organic food purchases. The mode displays the behavior of those never buying organic food, and this would explain the considerably different pattern of OLS which in turn averages the various frequencies of buying organic food. The same occurs if we move to the tails of the distribution of the dependent variable. The goal is to measure the impact on organic food purchases when the purchase frequency is very low or very high. This can be investigated by the quantile regressions. The fourth column in Table 4 reports the 75th quantile estimates of the regression model for the Italian sample. ${ }^{2}$ The mode regression shows that at low purchase frequency, the estimated coefficients are smaller, showing a reduced impact of the explanatory variables. Vice versa, at the 75th quantile, the estimates grow with respect to the median regression. In the right tail, fair pay, age, and education are not statistically significant, while price has quite a large negative impact for those who frequently buy organic food.

\section{The German case}

Unlike the Italian case, in Germany, the impact of the explanatory variables on organic food purchases generally increases when moving from OLS to the median. Education, fair pay, price, age, and ecological transportation are significant in both the German and Italian samples. Their impact is generally greater in the German sample, and, in absolute value, it grows in shifting from the mean to the median and the mode. In addition, young children, organic packaging, and absence of synthetic chemicals positively affect purchases of organic food. In this data set, the median regression models the behavior of those buying organic food two or three times a month, while the OLS estimates basically consider once-amonth buyers. Organic packaging, fair wages, and price are the variables showing the greatest change in moving from the OLS to the mode regression. Since the mode occurs at a high purchase frequency (once a week), the mode regression would model the behavior of those regularly buying organic food. In this sample, the mode coincides with the upper quartile and is not estimated. However, the left graph in Fig. 1 shows an almost bimodal distribution of organic food. The second highest frequency of this distribution coincides with the lower quartile, such that for rare buyers the 25 th quantile regression is computed. The comparison of the coefficients estimated at the quantiles, the columns of Table 4 headed median, 0.75 and 0.25 quantiles for the German data, shows a decreasing impact of education, declining from 0.14 at the first quartile to 0.12 at the median and 0.076 at the upper quartile. Price increases its discouraging effect at the higher frequencies of organic purchases, and the presence of young children reduces its relevance for frequent

\footnotetext{
${ }^{2}$ In Italy, the 25 th quantile is not computed since in this data set, the 25th quantile regression estimated coefficients are all equal to zero. However, the lower quartile coincides with the mode and is therefore investigated by the mode regression. In Germany, the lower and the upper quartiles can be both estimated by the quantile regression and the 75 th quantile coincides with the mode regression. The results are reported in Table 4 . To verify whether the changes in the estimated coefficients are statistically significant, interquantile regressions are implemented. In Italy, the differences from 50th to 75th quantiles are statistically significant in the following coefficients: $\Delta$ no chemicals $=0.1596 * *(t=2.74), \Delta$ certification $=0.1841^{* *}$ $(t=2.53)$ and $\Delta$ price $=-0.2650 * *(t=-3.09)$. This means that at the upper quartile, the impact of certification, of no chemicals, and of the negative impact of price increases significantly.
} 


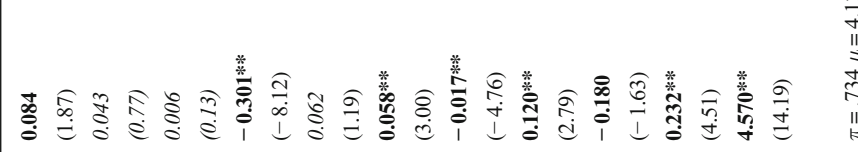

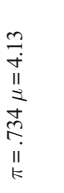

.ే

逍艺

동

s.

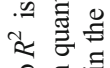

焉点.

要,

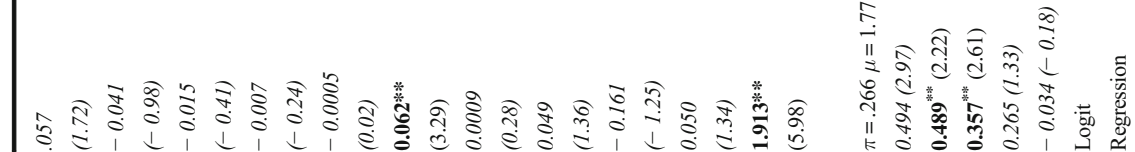

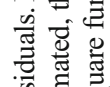

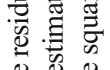

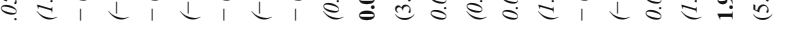

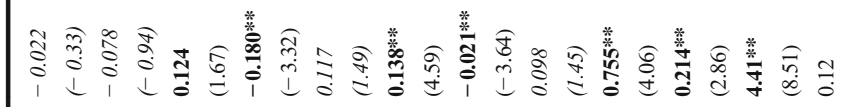

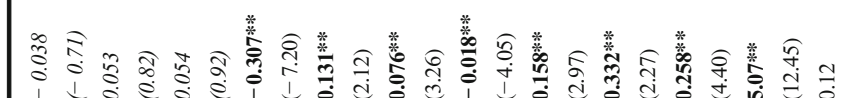

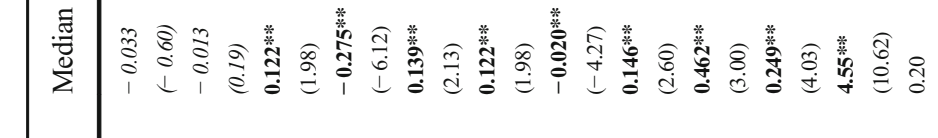

ฯ

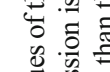

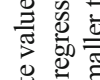

旁密

ఏి

类

言穿

㝳

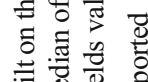

\&̊ำ

苛离

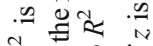

ㄴ.

공ㅎㅀ

\&

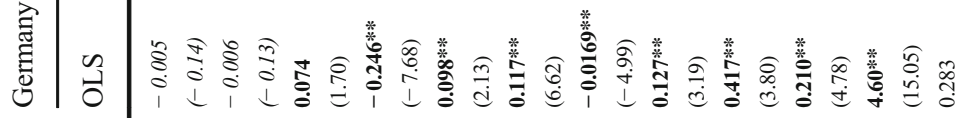

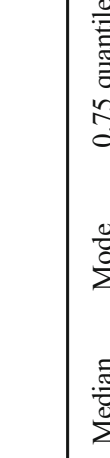

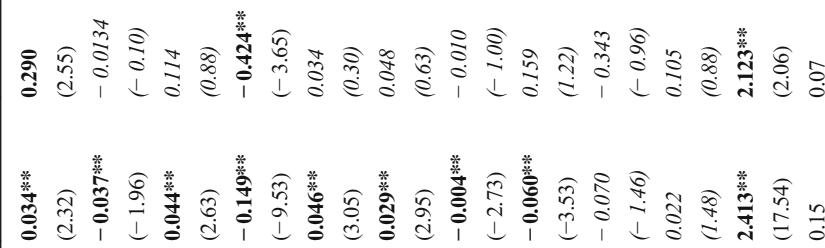

总

:

记

ఏి

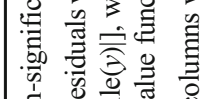

政

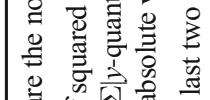

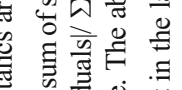

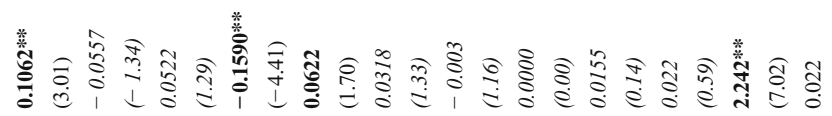

产

(2)

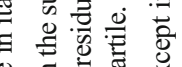

을 竞恶

3

亭

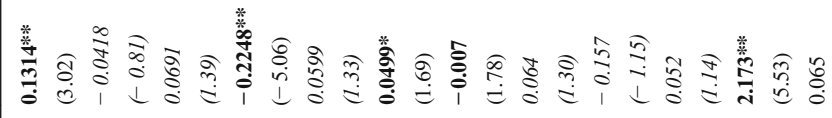

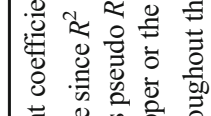

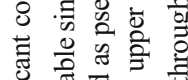

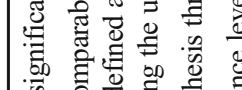

蒙

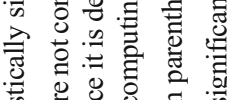

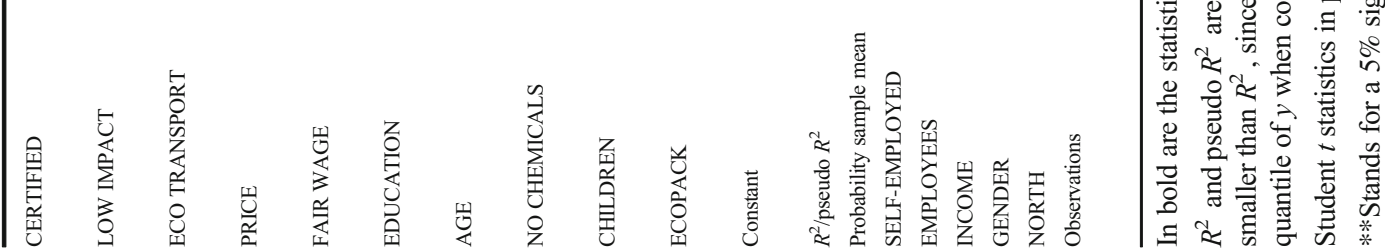


buyers. ${ }^{3}$ Fair pay and no chemicals are important for frequent buyers but are not statistically significant for rare buyers.

Alternatively, a different approach explicitly modeling the bimodality of this distribution can be considered. Such bimodality can be interpreted as the presence of two distinct groups of consumers, rare buyers and weekly buyers. The former has a frequency at the mode of 243 while the latter has frequency at the mode of 246 . In the finite mixture model, the regression coefficients are separately computed for each group. However, we do not know from which distribution an observation is drawn; the observed sample is incomplete since there is an unobservable latent variable $z$ which sorts one subsample from the other. The assumption is that each observed data point has a corresponding latent variable, specifying the group/component from which a data point is drawn. The estimation process, besides twice the number of coefficients, requires the estimate of the probability of belonging to one group or the other computed by a logit model. The results are reported in the last two columns of Table 4, while Fig. 2 depicts the predicted values of the distributions for each group of buyers, with sample mean $\mu=1.77$ for the first distribution, very close to the value of 2 , i.e., the lower mode, and $\mu=4.13$ for the other distribution, between 4 and 5 and close to the upper mode. The probability of belonging to a given group is related to buyers' characteristics like income, gender, employment, and region of residence of the household, and was estimated by logit. Due to the large number of non-respondents for the household income variable, 147, the probability model is computed in a smaller data set, $n=862$, as reported at the bottom of the table. Region is transformed into a dummy variable [NORTH] assuming unit value in 433 observations, ${ }^{4}$ while profession ranges from unemployed to retired, student, housewife, worker, agricultural sector, school/university teacher, manager, top manager, self-employed, and entrepreneur. This

\footnotetext{
${ }^{3}$ In Germany, comparison of 25th and 75th quantile regressions shows the following significant differences $\Delta$ price $=-0.1268 * *(t=-2.36)$, $\Delta$ education $=0.0609 * *(t=2.42), \Delta$ children $=0.4236 *(t=1.77)$, showing an increasing impact of these variables at the 75 th quantile. The comparison of 25th and 50th quantile regressions shows a significant increase in $\Delta$ education $=0.0448 * *(t=2.03)$, while the comparison between 50 th and 75 th quantile regressions provides significant differences for $\Delta$ price $=-0.0948 * *(t=-2.42)$ and $\Delta$ children $=0.2930 *(t=1.60)$.

${ }^{4}$ The northern regions are Bremen, Hamburg, Niedersachsen, Schleswigholstein, Nordrheinwestfalen, Brandenburg, Mecklenburgvorpommern, and Sachsenanhalt.
}

variable was split into two dummies, the first assuming value one for self-employed and entrepreneur in 112 observations [SELF-EMPLOYED], the second assuming value 1 for worker, agricultural sector, school/university teacher, manager, and top manager in a sample of 609 observations [EMPLOYEES]. Unemployed, retired, students, and housewives are the 288 remaining observations. The average probability of being in the rare buyers' group is $\pi=0.266$, while it grows to $\pi=0.734$ for the weekly buyers. These results are reported at the bottom of Table 4: in the bottom lines are the estimated average probabilities of an observation belonging to each group, $\pi$, and the average conditional mean within each group, $\mu$. Figure 3 depicts the probability of belonging to each group. The bottom section of the table reports the consumers' characteristics determining the probability of belonging to a group, the estimated coefficients of the logit model, and their $z$-test values in parenthesis. All the socioeconomic variables are selected to determine the probability of belonging to a group. Income and employees are statistically significant and have a positive impact on the probability of belonging to group $2 /$ weekly buyers, while self-employed, gender, and region are not statistically significant. ${ }^{5}$

Next, the regression model in each group is computed in a sample of size 1009. By modeling two separate distributions, one for rare and the other for frequent buyers, most explanatory variables are irrelevant in the rare buyers' subset, as shown in the second to the last column of Table 4. In this approach, rare buyers are not influenced in their purchasing habits by any of the explanatory variables but education. By contrast, in the weekly buyers' group, fair wage, environmental impact, and eco transport are the sole non-significant variables. All the other variables contribute to determine the weekly frequency of purchases in this group of buyers.

\section{Discussion}

The organic food market is relatively small, and consumers are characterized by different organic purchase frequencies. Indeed, analysis of German and Italian data shows the presence of buyers with a large range of purchasing frequencies. Germany has a per capita

\footnotetext{
${ }^{5}$ Income and profession could be correlated. The sample correlation between income and employees turns out to be low, 0.22. Even lower is the correlation between income and self-employed, 0.05 .
} 
Fig. 2 Estimated distributions of organic food in Germany as a mixture of two normal centered on differing means, $\mu=1.77$ for the distribution of rare buyers and $\mu=4.13$ for the distribution of weekly buyers

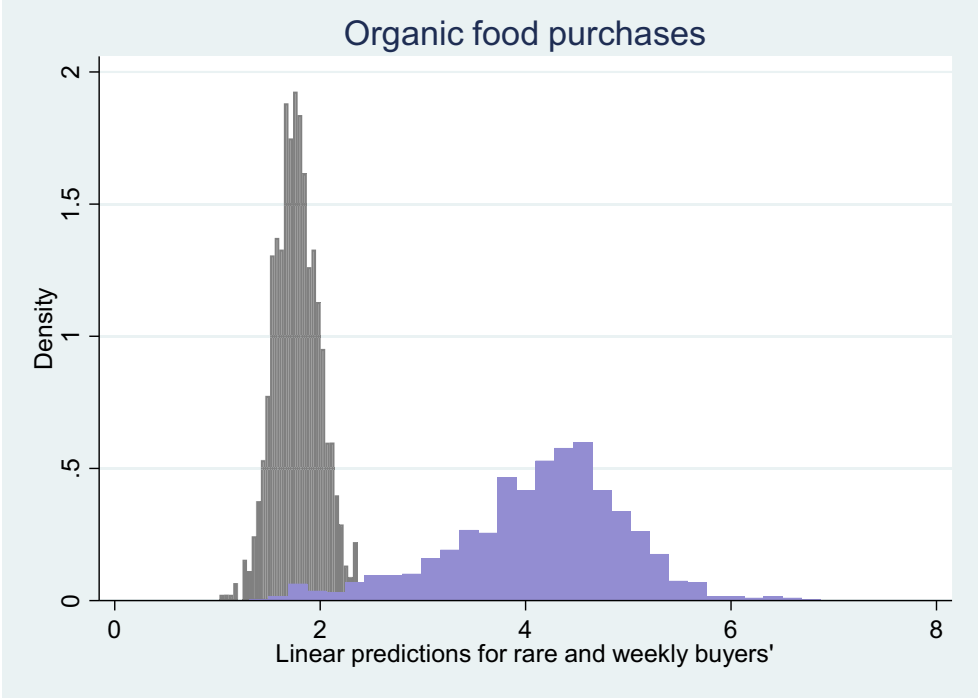

consumption of organic products that is almost triple than its Italian counterpart, and the two distributions are both skewed. The German distribution is left-skewed and the Italian is asymmetric to the right. In skewed distributions, mean, median, and mode differ from one another, and estimating the impact of independent variables on purchasing frequency with respect to the mean provides a limited picture. On comparing the estimates at different locations, it becomes clear that the impact of the covariates on organic food changes when looking at the mode or at the median or at the mean frequency of purchases. And it changes when measuring the impact on organic food purchases in the tails, at very low or very high purchase frequency using quantile regressions.

In Italy, the estimated coefficients reduce their impact on the dependent variable when shifting from occasional buyers to non-buyers of organic products. Italian frequent buyers are positively influenced by certified label and price. This agrees with the findings of Hughner et al. (2007) who identify health concerns as motives that mainly influence consumer preferences of organic foods. Less frequent buyers and non-buyers show a lower interest in these dimensions. With respect to food price, Italian less frequent buyers and non-buyers care less
Fig. 3 Probability of belonging to the rare or frequent buyers' group, computed as a function of socioeconomic characteristics. Group one probability averages at $\pi=0.266$ while group 2 averages at $\pi=0.733$

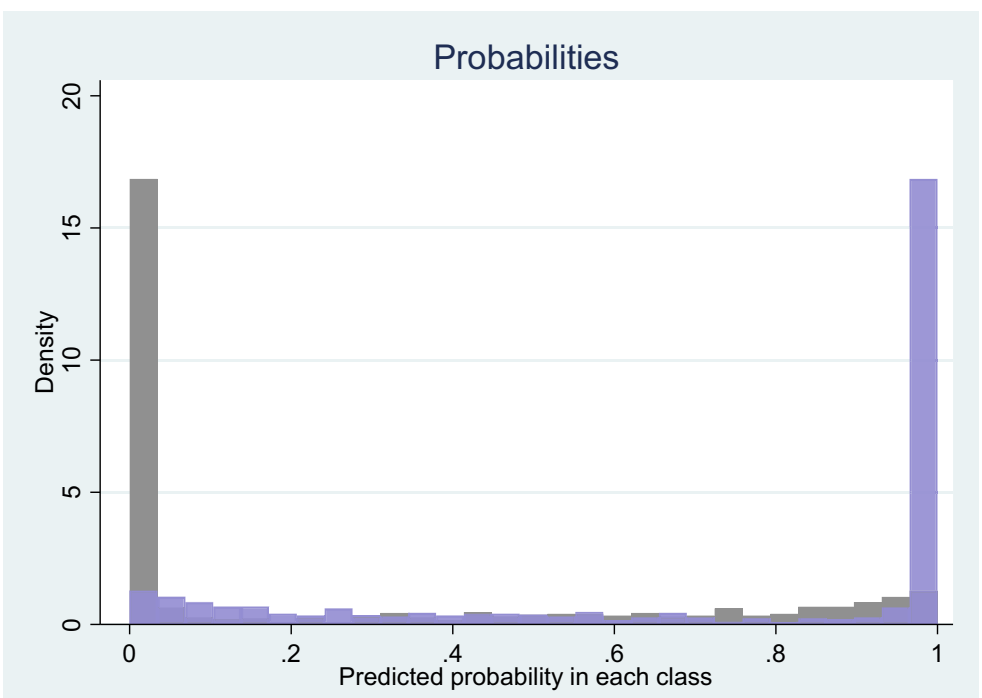


about such attributes. In this scenario, a possible strategy for consumers characterized by a low purchasing frequency could be a medium price strategy. This result agrees with the conclusions of Marian et al. (2014).

In Germany, the impact of the explanatory variables on organic food purchases increases from the mean to the median and the mode. Since few results are available on consumer perception of packaging of organic products, the positive impact on organic purchasing frequencies of organic packaging and fair wages is particularly interesting (Schleenbecker and Hamm 2013). In addition, due to the bimodality of this data set, a different approach was implemented that split the sample into two groups and considered the outcome as a mix of two distributions, for rare and for frequent buyers. By modeling two separate distributions, one for rare and the other for frequent buyers that coincide with the two modes of this distribution, most explanatory variables are irrelevant in the rare buyers' subset, and this segment is influenced only by education. Vice versa, in the weekly buyers, most of the variables contribute to determine the weekly frequency of purchases.

\section{Conclusions}

This paper investigated the determinants of organic food consumption in various market segments characterized by different purchasing frequencies. To the best of our knowledge, this is one of the few studies to investigate characteristics of organic consumers at different points of the distribution and consider two representative national samples. To estimate the impact of the independent variables on purchasing frequency different estimators of location were implemented. This is particularly important in the case of asymmetric distributions, as in the analyzed datasets, since it allows in-depth interpretation of the determinants of organic buying frequencies. The estimators implemented herein may be deemed of use for other products characterized by small market shares and by consumer segmentation. Their combined use provides insights into the market and allows forecasts to be improved and marketing strategies to be tailored. Moreover, thanks to sample representativeness, some suggestions can be drawn from the analysis, serving as input for further research and as a source of conjectures for organic operators.

The first major finding to emerge was the changing impact of the covariates on organic food along the distribution of purchase frequency, especially in the tails. This result is strategic for organic markets that are characterized by small consumer segments. More specific consumer profiling would allow tailored strategies to be implemented instead of a one-size-fits-all approach. The German case shows a growing impact of variables like education, fair pay, price, and ecological transportation moving from the mean to the mode of purchase frequency distribution. This evidence leads to different sets of communication strategies to reach rare or more frequent buyers. Multidimensional communication policies focusing on ethical (fair wages) and environmental (ecological transportation) aspects are more appropriate for regular/frequent consumers than for rare ones. German buyers are analyzed using two different distributions, one for rare and one for regular buyers, and the need for differentiated communication is quite evident.

In the Italian case, the results show a strong impact for occasional buyers. Education, certified label and ecological transportation have a positive impact on purchase frequency of organic food for this group of buyers. This market segment shows good expansion potential if stimulated with specific communication policies.

Our results provided valuable information on two important general aspects. The first was to point out the deep differences among frequent, regular, and rare buyers. This evidence is strategic for food markets characterized by a small-size segment. The second aspect was to stress the need for specific communication policies for different segments in national markets with different life cycle stages. In the more mature German organic sector, multidimensional communication policies, focusing on ethical (fair wages) and environmental (ecological transportation) aspects are more appropriate for regular/frequent consumers. By contrast, for rare consumers, this strategy does not work. In the Italian case, where the organic market is still at an initial stage, a strong impact is discovered for occasional buyers. Thus, implementing multidimensional communication policies focusing on ethical and environmental aspects could gradually enlarge the size of organic consumption.

Further research is needed to identify the right marketing tools to support markets with small-size segments. Such support could well be useful for the organic sector, and generally for products where ethical attributes have a major impact on purchase. 
Funding Open access funding provided by Università degli Studi di Napoli Federico II within the CRUI-CARE Agreement.

Open Access This article is licensed under a Creative Commons Attribution 4.0 International License, which permits use, sharing, adaptation, distribution and reproduction in any medium or format, as long as you give appropriate credit to the original author(s) and the source, provide a link to the Creative Commons licence, and indicate if changes were made. The images or other third party material in this article are included in the article's Creative Commons licence, unless indicated otherwise in a credit line to the material. If material is not included in the article's Creative Commons licence and your intended use is not permitted by statutory regulation or exceeds the permitted use, you will need to obtain permission directly from the copyright holder. To view a copy of this licence, visit http://creativecommons.org/licenses/by/4.0/.

\section{References}

Annunziata A, Vecchio R (2016) Organic farming and sustainability in food choices: an analysis of consumer preference in Southern Italy. Agric Agric Sci Procedia 8:193-200

Arnot C, Boxall PC, Cash SB (2006) Do ethical consumers care about price? A revealed preference analysis of fair-trade coffee purchases. Can J Agric Econs 54(4):555-565

Baudry J, Péneau S, Allès B, Touvier M, Hercberg S, Galan P, Kesse-Guyot E (2017) Food choice motives when purchasing in organic and conventional consumer clusters: focus on sustainable concerns (the NutriNet-Santé cohort study). Nutrients 9(2):88

Bi X, Gao Z, HouseL A, Hausmann DS (2015) Tradeoffs between sensory attributes and organic labels: the case of orange juice. Int J Consum Stud 39(2):162-171

Buder F, Feldmann C, Hamm U (2014) Why regular buyers of organic food still buy many conventional products: productspecific purchase barriers for organic food consumers. $\mathrm{Br}$ Food J 116(3):390-404

Cicia G, Del Giudice T, Scarpa R (2002) Consumers' perception of quality in organic food: a random utility model under preference heterogeneity and choice correlation from rankorderings. Br Food J 104(3/4/5):200-213

Cicia G, Del Giudice T, Ramunno I (2009) Environmental and health components in consumer perception of organic products: estimation of willingness to pay. J Food Prod Mark 15(3):324-336

Cicia G, CembaloL, Del Giudice T, Scarpa R (2013) Country-oforigin effects on Russian wine consumers. J Food Prod Mark 19(4):247-260

de Magistris T, Gracia A (2008) The decision to buy organic food products in Southern Italy. Br Food J 110(9):929-947

de Magistris T, Gracia A (2016) Consumers' willingness-to-pay for sustainable food products: the case of organically and locally grown almonds in Spain. J Clean Prod 118:97-104

Dekhili S, Sirieix L, Cohen E (2011) How consumers chooseolive oil: The importance of origin cues. Food Qual Prefer 22(8): 757-762

Denver S, Jensen JD (2014) Consumer preferences for organically and locally produced apples. Food Qual Prefer 31:129-134
Di Fonzo A, Liberati C (2020) Consumers are unaware about European legislation on communication of the health benefits conveyed by claims. An empirical survey. Ital Rev Agric Econ 75(1):51-59

Du S, Bartels J, Reinders M, Sen S (2017) Organic consumption behavior: a social identification perspective. Food Qual Prefer 62:190-198

Gerini F, Alfnes F, Schjøll A (2016) Organic-and animal welfarelabelled eggs: competing for the same consumers? J Agric Econ 67(2):471-490

Grunert KG (1996) Authomatic and strategic processes in advertising effects. J Market 60(4):88-101

Hall CR, Campbell BL, Behe BK, Yue C, Lopez RG, Dennis JH (2010) The appeal of biodegradable packaging to floral consumers. HortScience 45(4):583-591

Hansen LG, Andersen LM (2013) Does organic crowding out influence organic food demand? Evidence from Danish micro panel. University of Copenhagen IFRO w. p. n. 2013/2, $1-42$

Hempel C, Hamm U (2016) How important is local food to organic-minded consumers? Appetite 96:309-318

Hughner RS, McDonagh P, Prothero A, Shultz CJ, Stanton J (2007) Who are organic food consumers? A compilation and review of why people purchase organic food. J Consum Behav 6(2-3):94-110

Hwang CG, Lee YA, Diddi S (2015) Generation Y's moral obligation and purchase intentions for organic, fair-trade, and recycled apparel products. Int J Fashion Des Technol Educ 8(2):97-107

Italian Trade Agency - ICE (2018) Il mercato tedesco dei prodotti biologici.ICE Berlino- Agenzia per la promozione e l'internazionalizzazione delle imprese italiane

Jensen KD, Denver S, Zanoli R (2011) Actual and potential development of consumer demand on the organic food market in Europe. NJAS-Wageningen J Life Sci 58(3-4):79-84

Kemp G, Santos Silva J (2012) Regression toward the mode. J Econ 170:92-101

Klokner H, Langen N, Hartmann M (2013) COO labeling as a tool for pepper differentiation in Germany. Brit Food J 115(8): 1149-1168

Koenker R (2005) Quantile regression. Cambridge University Press, Cambridge UK

Koutsimanis G, Getter K, Behe B, Harte J, Almenar E (2012) Influences of packaging attributes on consumer purchase decisions for fresh produce. Appetite 59(2):270-280

Krystallis A, Fotopoulos C, Zotos Y (2006) Organic consumers' profile and their willingness to pay (WTP) for selected organic food products in Greece. J Int Consum Mark 19(1):81106

Krystallis A, Vassallo M, Chryssohoidis G (2012) The usefulness of Schwartz's 'Values Theory' in understanding consumer behaviour towards differentiated products. J Mark Manag 28(11-12):1438-1463

Lee J (1989) Mode regression. J Econ 42:337-349

Lee HJ, Yun ZS (2015) Consumers' perceptions of organic food attributes and cognitive and affective attitudes as determinants of their purchase intentions toward organic food. Food Qual Prefer 39:259-267

Marian L, Chrysochou P, Krystallis A, Thøgersen J (2014) The role of price as a product attribute in the organic food context: 
an exploration based on actual purchase data. Food Qual Prefer 37:52-60

Naspetti S, Zanoli R (2009) Organic food quality and safety perception throughout Europe. J Food Prod Mark 15(3): 249-266

Panico T, Del Giudice T, Cicia G, Cembalo L (2011) Consumption of organic strawberries in Italy: demand analysis. New Medit 10(3):11-16

Pearson D, Henryks J, Sultan P, Anisimova T (2013) Organic food: exploring purchase frequency to explain consumer behavior. J Org Syst 8(2):50-63

Profeta A, Balling R, Roosen J (2012) The relevance of origin information at the point of sale. Food Qual Prefer 26(1):1-11

Scarpa R, Del Giudice T (2004) Market segmentation via mixedlogit: extra-virgin olive oil in urban Italy. J Agric Food Ind Organ 2(1) article 7

Schleenbecker R, Hamm U (2013) Consumers' perception of organic product characteristics. A review. Appetite 71:420 429

Verain MC, Sijtsema SJ, Antonides G (2016) Consumer segmentation based on food-category attribute importance: the relation with healthiness and sustainability perceptions. Food Qual Prefer 48:99-106

von Meyer-Höfer M, Nitzko S, Spiller A (2015) Is there an expectation gap? Consumers' expectations towards organic: an exploratory survey in mature and emerging European organic food markets. Br Food J 117(5):1527-1546

Wee CS, Ariff M, Zakuan N, Tajudin M, Ismail K, Ishak N (2014) Consumers perception, purchase intention and actual purchase behavior of organic food products. Rev Integrat Bus Econ Res 3(2):378

Yiridoe EK, Bonti-Ankomah S, Martin RC (2005) Comparison of consumer perceptions and preference toward organic versus conventionally produced foods: a review and update of the literature. Renew Agric Food Syst 20(4):193-205

Zander K, Hamm U (2010) Consumer preferences for additional ethical attributes of organic food. Food Qual Prefer 21(5): 495-503

Zander K, Hamm U (2012) Information search behaviour and its determinants: the case of ethical attributes of organic food. Int J Consum Stud 36(3):307-316

Zanoli R, Naspetti S (2002) Consumer motivations in the purchase of organic food: a means-end approach. Br Food J 104(8): 643-653

Publisher's note Springer Nature remains neutral with regard to jurisdictional claims in published maps and institutional affiliations. 